\title{
Occupational medicine in the National Health Service
}

\author{
Ian S. Symington \\ Director-Occupational Health Service, Greater Glasgow Health Board, 20 Cochrane Street, \\ Glasgow G1 1JA, UK
}

\section{Introduction}

For many doctors working within the National Health Service (NHS), occupational medicine remains a specialty on the fringe of their awareness. Undergraduate exposure to the subject is limited in most medical schools and at postgraduate level health and safety training in relation to medical work is given little emphasis. The fact that the majority of those who work in occupational medicine are employed outside the NHS in commercial enterprises or government departments has tended to isolate them further from the mainstream of medical activity.

During the past 15 years much has been done to overcome these barriers. The establishment of occupational medicine as a specialty within the framework of the Joint Committee for Higher Medical Training (JCHMT) has been one major advance which has led to the creation of posts considered acceptable for training and of a standard equivalent to other medical disciplines. There are now over 100 senior registrars working in approved training posts of this kind, most of which are outside the Health Service. In tandem with this development, the Faculty of Occupational Medicine within the Royal College of Physicians of London was established in 1978 with three major objectives: to promote the advancement of knowledge in occupational medicine; to act as an authoritative consultative body; and to develop and maintain high standards of training, competence and professional integrity. These two initiatives have done much to raise the profile of occupational medicine and already many doctors are being attracted into an emerging specialty which combines clinical skills with a strong emphasis on health promotion and the prevention of ill health in the workplace.

Correspondence: I.S. Symington, M.B., Ch.B., F.F.O.M., F.R.C.P.(G.).

Accepted: 13 February 1992
Within the NHS itself a further major development is taking place through the gradual establishment of Occupational Health (OH) Services for NHS staff, including medical staff, in hospitals and the community. This more direct interface with the profession may help to enable better understanding of the main aims of $\mathrm{OH}$ activity and achieve higher levels of professional collaboration than have existed in the past.

\section{Development of NHS Occupational Health Services}

\section{Barriers to development}

While $\mathrm{OH}$ Services have been established in most large industries within the United Kingdom for many years, it is only comparatively recently that their development has been seriously considered for the one million employees within the NHS.

A number of factors may have inhibited development. These include the widely held perception that the NHS is a relatively safe place in which to work, but when objective comparisons are made with other organizations it is clear that this view is not entirely justified. The higher relative risk for a number of occupationally related infections in groups of health care workers certainly merits concern. The epidemic of work-induced back problems, particularly in nursing staff, is comparable in scale with that found in mining and steel manufacturing, and the range of hazardous chemicals handled by a large health authority $(8,000$ substances were recorded in one) is equivalent to that encountered even in parts of the chemical industry itself.

While some industries such as the lead industry have had longstanding legal requirements to undertake health surveillance of the workforce, it is only within the last 20 years that the NHS has become subject to formal legislation. In other industries the need for optimum physical fitness to cope with a particular task has led to close medical 
scrutiny, but it has only been recently appreciated that the energy expenditure expected of nurses working in high dependency units is comparable with some of the heavier tasks commonly undertaken on construction sites.

Even where no major hazards caused by work exist, many employers have taken the view that promoting $\mathrm{OH}$ Services for staff may contribute to the health of their employees. In return they expect greater efficiency, increased productivity and lower absenteeism. In any labour-intensive organization even small increments in the health status of employees can be of major benefit to the overall efficiency of the organization but NHS management has tended to be cautious in putting this hypothesis to the test.

\section{Stimulus for development}

As early as 1968 a joint committee of the Ministry of Health and the Scottish Home and Health Department (the Tunbridge Committee), set up to report on the need for OH Services in the NHS, made a detailed study of services in a number of major industries and concluded that the concept should be extended to the NHS. ${ }^{1}$ This led to the establishment of some pilot services in the early 1970s but coordinated development did not follow until later.

The major stimulus towards change occurred in 1974 through the establishment of the Health and Safety at Work Act and its subsequent regulations. This has contributed substantially to increased public awareness of health and safety issues in the workplace and has also placed responsibilities on the employer 'to ensure, as far as is reasonably practicable, the health, safety and welfare at work of all his employees.' Health care workers were formally incorporated into this legislation in 1976 and in 1978 the Health and Safety Commission established a separate Health Services Advisory Committee, comprising representatives of NHS management and NHS trades unions, to consider items of concern, and to produce agreed advisory guidance which health authorities could use to help fulfil their Health and Safety responsibilities. The range of documents published to date is listed in Table I.

In 1986, the NHS (Amendment) Act finally removed the protection of Crown Immunity from health authorities in relation to health and safety at work. Although in theory this has not substantially altered the responsibility of a health authority, it does place a more identifiable commitment on its chairman and management, who can now be held personally or collectively responsible for breaches of health and safety legislation. The lessons learned from the disasters at King's Cross, Zeebrugge and Piper Alpha have documented how heavy the
Table I Health Services Advisory Committee publications

Title

The Safe Disposal of Clinical Waste

Asbestos Hazard in Health Service Buildings:

A Pocket Warning Card for Works Staff

Safety Policies in the Health Service

The Lifting of Patients in the Health Services

Guidelines on Occupational Health Services in the Health Service

A List of Guidance on Health, Safety and Welfare in the Health Service

Safety in Health Service Laboratories: Hepatitis B

AIDS: Prevention of Infection in the Health Service: A Fact Sheet for Staff

Guidance on the Recording of Accidents and Incidents in the Health Services

Safety in Health Service Laboratories:

The Labelling, Transport and Reception of Specimens

Violence to Staff in the Health Services

Safety in Health Service Laboratories: Safe Working and the Prevention of Infection in Clinical Laboratories

Safety in Health Service Laboratories: Safe Working and the Prevention of Infection in the Mortuary and Post-mortem Room

Safety in Health Service Laboratories:

Safe Working and the Prevention of Infection in Clinical Laboratories - Model Rules for Staff and Visitors

weight of that responsibility can be.

Despite the initial impetus of the Tunbridge 3 Report, little progress was made during the remainder of the 1970s. Yet a study ${ }^{2}$ commissioned by the Employment Medical Advisory Service indicated $\overline{ }$ that substantial investment had been made in terms $\stackrel{3}{.}$. of personnel employed. Approximately 100 whole $\frac{5}{3}$ time equivalent (WTE) occupational physicians and 600 WTE occupational health nurses were identified in occupational health services within the NHS in England and Wales at that time. The $\frac{O}{5}$ overall picture was of a large number of part-time $\rightarrow$ doctors and full-time nurses working in an uncoordinated framework with little effective leader- $N$ ship. Most of the doctors and more than $50 \%$ of the nurses had not received specific training for the $\mathcal{N}$ work being carried out, and apart from a few $\omega$ notable exceptions, it was felt that most services were not realizing their full potential. Agreement to create NHS consultant posts in occupational $\Phi^{\Phi}$ health was therefore seen as a major step towards ${ }^{?}$ better development and coordination of services. $\frac{T}{T}$ In 1981 the first consultant appointment was made $\frac{\overrightarrow{\mathrm{O}}}{\mathrm{O}}$ in Scotland and since then over 50 posts have been $\stackrel{\odot}{\square}$

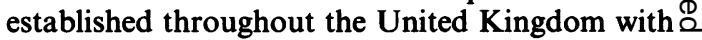


more in the planning stages. Arguably, this represents the fastest growing medical specialty within the NHS during the past decade, but most of the necessary resources have been funded through rationalization of existing non-consultant posts when vacancies arose. With similar recruitment of properly trained staff to key occupational health nursing posts, $\mathrm{OH}$ services in the NHS are constantly improving in quality and scope.

The Society of Occupational Medicine (SOM) deserves credit for facilitating communication in this development through the establishment in 1983 of the SOM NHS Work Group. The group established a regional communications network with the majority of doctors (full-time and parttime) working in NHS Occupational Health and published a series of discussion documents and guidance notes (Table II) on priority topics covering aspects of organization, ethics and practice. From this group has developed an Association of NHS Occupational Physicians (ANHOPS) which is continuing with these tasks and extending its interest into the coordination of research.

\section{Objectives of an NHS Occupational Health Service}

Even where they are established, the main objectives of an NHS Occupational Health Service are not always fully apparent to hospital doctors. The International Labour Organisation in its Recommendation Number 112 (1959), ${ }^{3}$ which was subsequently endorsed both by the EC Commission and the Committee of Ministers of the Council of Europe defined the broad purposes as follows:

(a) protecting the workers against any health hazard which may arise out of their work or the condition in which it is carried on;

(b) contributing towards the workers' physical and mental adjustment, in particular by the adaptation of the work to the workers and their assignment to jobs for which they are suited;

(c) contributing to the establishment and maintenance of the highest possible degree of physical and mental well-being of the workers.

The achievement of these objectives will involve the efforts of a multi-disciplinary team which can include: an occupational physician; an occupational health nurse with appropriate postgraduate training and qualifications in this field; an occupational hygienist with expertise in measuring contaminants in the working environment and advising on development of safe systems of work; and clerical support staff. When the consultant in occupational health has specialist accreditation in occupational medicine and is full-time, he or she is normally expected to lead the team. The consultant
Table II Guidance notes for occupational physicians produced by a working group of the Society of Occupational Medicine and the Association of NHS Occupational Physicians

Title Date

Health Assessment of Applicants for Nurse 1985

Training

Prevention of Hepatitis B in NHS Staff

1985

Alcohol Abuse and a Draft Policy for Problem 1986 Drinking

Health Assessment of Applicants for Entry to 1986 Schools of Physiotherapy

Protection of NHS Workers against Tuberculosis

Referrals to Occupational Health Departments 1986

Ambulance Staff - Health Assessment and Medical Supervision

Confidentiality of Records and Ethical

Relationships for Occupational Health Staff in the NHS

Health Assessment for Employment in the NHS 1987

Operational Policy for Occupational Health Services in the NHS

Pregnancy and Employment in the NHS, 2nd ed

also requires to relate to many other groups including NHS managers; trade union representatives; personnel staff; hospital engineers; radiation protection advisers; safety officers; occupational psychologists and others (Figure 1).

\section{Functions of an NHS Occupational Health Service}

The range of functions of the $\mathrm{OH}$ team will depend on the type of health authority served and the adequacy of the funding arrangements. Within the ideal $\mathrm{OH}$ service, however, an extensive range of facilities can be made available to NHS employees and management. Some of these are as follows:

\section{Health hazard evaluation services}

(a) Workplace visits Occupational Health staff are often involved in visiting work areas to familiarize themselves with working conditions and to investigate situations where the environment is suspected of contributing towards health problems. When potential problems are identified, appropriate action can be taken to effectively reduce the level of risk.

(b) Occupational hygiene services Many occupational health services have access to simple equipment for measuring aspects of the working environment such as noise, dusts or gases. Occupational hygienists, where they are established, are 


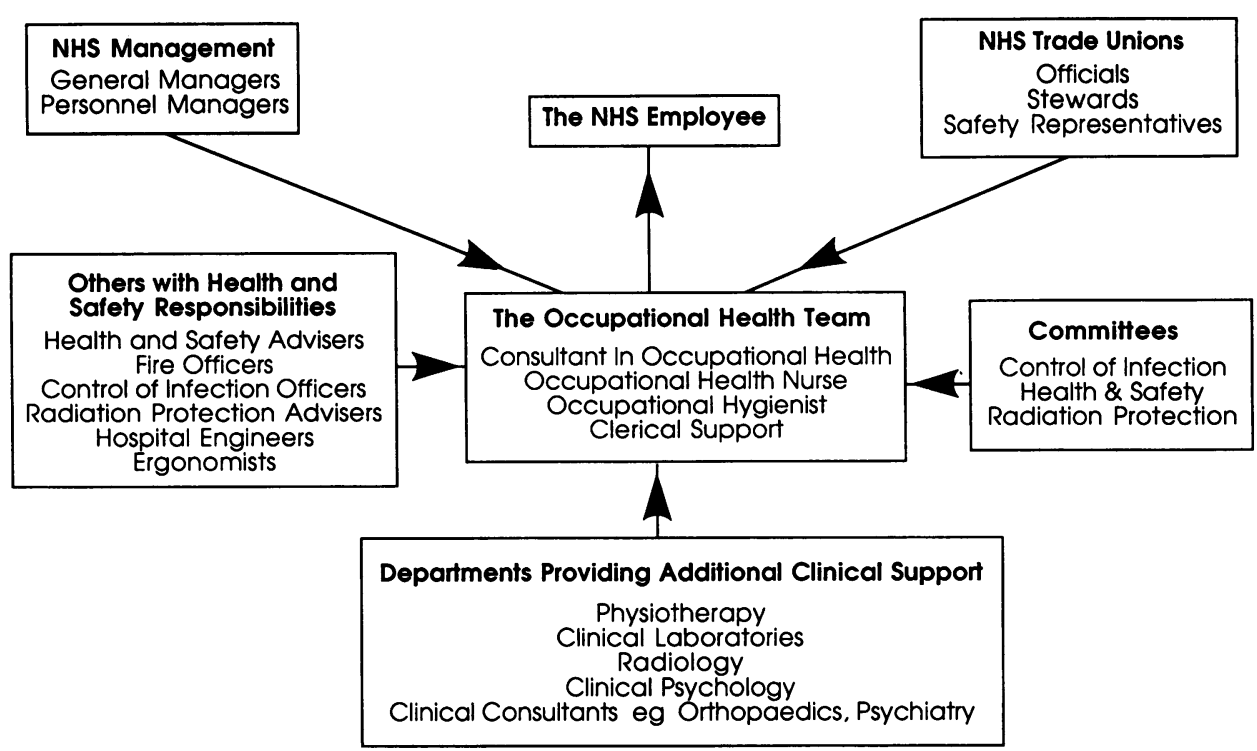

Figure 1 Liaison required for effective occupational health care in the NHS.

usually supported by a wider range of sophisticated technology to enable more detailed measurement of contaminants and relate these to established occupational exposure standards. Glutaraldehyde exposure is one topical example where occupational hygiene assessment can be of considerable help in risk assessment, enabling rational prioritizing of action at the most heavily contaminated sites.

(c) Investigations and surveys Sometimes more extensive studies of working populations are required involving biological and environmental measurement, often in conjunction with other clinical departments. Some OH Departments, for example, undertake back pain prevention programmes to identify highly vulnerable groups who might benefit from appropriate training with mechanical lifting techniques. Assessment of routine data such as hospital accident statistics can assist with prioritizing the problems and finding the solutions. In one health authority, three serious ladder accidents occurring in different hospitals led to a more detailed 'safe system of work' designed to eliminate the problem.

\section{Advisory services}

(a) Influencing general policy The creation of a safe and healthy working environment cannot be achieved effectively without the wholehearted determination of senior management. Organizations that have achieved high standards of occupational health and safety are those that have incorporated this ideal as an integral part of total quality management. Studies by the Health \& Safety Executive's Accident Prevention Advisory Unit have made a convincing economic case that good health and safety management means good business. Staff in occupational health services try hard to advocate this philosophy to senior management and influence health authorities to develop effective health and safety management systems which can be audited and refined as necessary.

(b) Influencing specific policy While most health authorities have by now fulfilled the requirement to draw up a general health and safety policy, it is also necessary to develop more detailed policies on issues of concern. These policies have to be readily understood and appropriate training given to those who are involved. Occupational Health Service staff with their understanding of the risks and the legal requirements are well placed to assist. The steady stream of new Health \& Safety legislation will provide a ready source of material to work on Apart from occupational health and safety issues, $\mathrm{OH}$ staff are also involved in influencing other policies that affect staff such as workplace smoking policy; alcohol recovery programmes; and dealing with disabled employees.

\section{Control of infection services}

Organization of immunization programmes for NHS employees requires considerable clinical and 
administrative effort if appropriate protection is to be provided. An effective recall system can ensure updates at the proper intervals. Hepatitis $B$ vaccine is currently included in these programmes and all clinical medical staff should ensure that they receive this vaccine. For those travelling overseas on health service business appropriate advice and, if necessary, immunization can be provided.

Counselling and follow-up are undertaken following needlestick and similar incidents where employees are concerned about hepatitis B and/or HIV infection.

'Sentinel' cases of occupational infection such as pulmonary tuberculosis and hepatitis B are fully investigated to identify causative factors and recommend changes in policy if indicated. $\mathrm{OH}$ staff also participate in the activities of Control of Infection Committees and contribute to the surveillance arrangements through these routes.

In conjunction with control of infection staff, occasional studies are mounted to assess infection prevalence in groups of staff. Outbreaks of methicillin-resistant staphylococcus aureus (MRSA), for example, cause great concern in hospitals. Community outbreaks of chickenpox also cause alarm when known contacts who have not been previously infected are nursing vulnerable patients.

\section{Health promotion activities}

Health promotion activities within the NHS workforce can bring personal benefit to the individual employee. They can also enhance the concept of the 'exemplar role' of the health professional and also of the health authority as an organization which practises what it preaches. Occupational health staff are often involved in the development of strategies for dealing with control of smoking in the workplace and alcohol policies in relation to employment.

\section{Counselling and welfare services}

A confidential counselling service can be provided to employees by Occupational Health Nurses with counselling experience. Where occupational factors contribute to stress, efforts are made to improve the working situation. Pregnant employees have particular concern about their working environment and seek advice on issues such as exposure to cytotoxic drugs or anaesthetic gases. In most situations normal duties can be safely continued, but a pragmatic policy of providing alternative duties for those who remain unduly concerned after full counselling is operated in most health authorities. Other problems include: dependencies on alcohol and drugs, post-traumatic stresses, concern about blood-borne diseases and general health issues.

\section{Health assessments}

Most occupational health services have arrangements for screening potential employees to ensure adequate fitness to undertake specific duties. Such arrangements are normally handled by a trained occupational health nurse, who has access to medical advice from an occupational health physician in cases causing concern.

Following exposure to a specific occupational hazard assessments are undertaken to ascertain whether a health problem is known or suspected to be work related. Complaints of nurses wheezing at work, for example, led to an investigation ${ }^{5}$ which linked the symptoms to the use of a chlorhexidine in alcohol aerosol spray. Conversion to a simple manual technique eliminated the problem.

Following long-term or intermittent short-term absence from work through ill health or injury, assessment is undertaken at the request of managers or personnel officers, to provide advice on any individual whose absence is causing concern. Every effort is made to identify health factors likely to improve attendance and assist the individual. In particular, care is taken not to overlook occupationally related ill health. Issues of rehabilitation and early retiral on health grounds are also considered. Where levels of absence appear to be high in a specific department or group of employees the $\mathrm{OH}$ service is available to make a wider assessment of factors which may be relevant.

When a health problem may affect health and safety at work assessments are undertaken at the request of managers. Examples include the catering worker with a bowel infection, the driver who develops loss of consciousness, and the nurse with progressive visual deterioration.

Regular health surveillance in relation to a specific occupational exposure is conducted at regular intervals and may be required by specific health and safety legislation such as the Control of Substances Hazardous to Health (COSHH) Regulations ${ }^{7}$ which also applies to microbiological substances. Some examples are:

clerical staff operating VDUs - vision test at entry;

laboratory animal workers - routine lung function tests and general questionnaire to detect early allergic disease;

high-risk tuberculosis workers - annual questionnaires to identify possible infection;

glutaraldehyde exposure worker - annual health questionnaire to detect early allergic disease.

When there is concern about work performance or behaviour at work it is important that managers do not overlook possible underlying health problems. Such assessments are often undertaken when health problems are suspected to be contributory 
factors. These referrals include situations covered within policies on alcohol and drugs in relation to employment.

\section{Training and information services}

Although hospitals are never far from some source of assistance, the current first-aid regulations ${ }^{6}$ require proper arrangements to be identified, particularly for those working in areas far from casualty departments, e.g. dining rooms, laboratories and laundries. Occupational health staff can advise on requirements. Under the regulations, first-aid training programmes require to be approved by the Health and Safety Executive and a number of NHS occupational health services now hold authorization to carry out this training.

Members of the $\mathrm{OH}$ team can make regular contributions to in-service training courses on subjects which include: organizing for health and safety, Health \& Safety legislation, coping with the Control of Substances Hazardous to Health (COSHH) regulations, preventing back injuries, and managing stress at work. Many $\mathrm{OH}$ departments can also provide up to the minute information on toxic substances through access to library and computer databases covering all aspects of workplace hazards.

\section{Role of the NHS consultant in occupational health service provision for the NHS}

The main role of the NHS occupational health consultant is to provide leadership within the occupational health departments delivering a range of high-quality services described above. Their contribution to occupational health practice on a wider basis is also possible and like their medical colleagues in other disciplines, many are active in teaching and research.

\section{Teaching}

The existing input to occupational health training for undergraduate medical students has already been identified as a deficiency in the curriculum of most medical schools. ${ }^{8}$ In health authorities where there are teaching commitments, NHS consultants in occupational health are well placed to contribute to and facilitate the development of occupational medicine teaching in collaboration with university colleagues. A number of initiatives have already been established often involving other hospital consultants and occupational physicians in industry outside the NHS. It is feasible to ensure, within existing clinical teaching, that courses covering, for example, ear, nose and throat surgery, respiratory medicine, dermatology and psychiatry emphasize the occupational aspects. Within the broad dimension of public health teaching programmes there is also scope to ensure that an occupational health component is established. In postgraduate medical education a network of short introductory courses in occupational medicine, approved by the Faculty of Occupational Medicine, has been set up to meet the needs of both general practitioners and hospital doctors who wish to learn more about the subject. These are proving to be a popular addition to the range available.

\section{Research and audit}

Research into occupational health problems in the NHS is an area with considerable potential for growth and many of the new $\mathrm{OH}$ consultants are grasping the challenge with vigour. Through close contact with colleagues in clinical and laboratory specialties there are opportunities for multidisciplinary collaboratve research on groups of employees at special risk. While such activity is still at an early stage of development, the Research Panel of the Association of NHS Occupational Physicians is now established and is active in trying to stimulate interest in research work; to help find suitable sources of funding; and to make best use of scarce manpower resources. Medical audit can alse usefully be considered within this spectrum as most of the systems used in occupational health practice require to be critically evaluated. Many NHS OH departments have now established audit procedures designed to ensure high-quality standards in the work done.

\section{Clinical practice}

It has been shown in some health authorities that referral networks can be developed between the consultant in occupational health and colleagues in hospital and general practice with a view to assisting with the clinical management of those patients who may have work-related health problems. When used as an information resource on work/ health interactions such contacts can range from general telephone advice to full clinical assessment of individual patients. Those consultant occupational physicians with practical experience in toxicology and epidemiology are also able to contribute to the assessment of environmental problems which affect the public health outside the hospital environment. In some areas, this has led to close links being forged between NHS occupational health consultants and specialists in public health and environmental health.

\section{Services to organizations outside the NHS}

Further major opportunities for development are being presented by the new NHS management 
changes. Once established, and having reached the critical mass required to function effectively, the capacity of NHS occupational health services to extend their activity to organizations outside the NHS has not gone unnoticed by the income generation' strategists. Such activities are already being developed in some health authorities and the range of organizations to which services are provided includes local authorities, fire authorities, educational establishments, construction companies, manufacturing industries and many others. These activities serve to increase substantially the number of employees covered by expert occupational health services and at the same time provide additional professional diversity, and opportunities for teaching and research in a wider range of occupational environments. Those who negotiate additional contracts of this kind should, however, take pains to ensure that the new activity is not diverting resources away from the existing provision of services to NHS employees. At the same time, with the increasing pace of change towards contracting out of ancillary services, development of independent hospital trusts and collaborative links with the private sector, it is important for the purchasing authority not to lose sight of the need to maintain adequate levels of occupational health provision in the units with which it is contracting.

Whatever the nature of the $\mathrm{OH}$ contract with the purchasing organization, whether within or outside the NHS, agreement should be reached if the schemes are truly income generating as to how the new resources should be utilized. If at least a proportion of this income could be guaranteed to develop better occupational health services or promote occupational health research, there would be stronger incentives for $\mathrm{OH}$ staff to participate wholeheartedly.

\section{Can NHS Occupational Health Services benefit medical staff?}

\section{Doctors as an 'at-risk' occupational group}

Medical staff comprise a very small percentage of the total NHS working population and it follows that most of the efforts of occupational health services will therefore relate to non-medical grades. The medical group, however, is the most influential and, pro rata, the most expensive manpower resource within the NHS. It is certainly the most knowledgeable about health issues and probably the best equipped to look after its own health on an individual basis. Sickness absence rates in this group are among the lowest of all grades within the NHS although mortality from alcohol-related problems and suicide remains higher than that encountered in the general population. It is, perhaps, the most ambivalent group when it comes to confronting the health problems which relate to its own work and can be among the most resistant to accepting routine measures designed to provide protection. Part of the profession's defence mechanism against the daily exposure to death and serious morbidity understandably includes an element of denial - 'it can't happen to me'. Yet doctors in the course of their work are not completely immune to infections such as hepatitis B, pulmonary tuberculosis or HIV. Nor are they specially protected from the long tolerated health effects and inefficiency which arises from working prolonged hours without sleep. They can be the most difficult to coax into compliance with current immunization schedules recommended by the health departments and have until recently tended to resist reform of junior doctors' hours. The presence of a conveniently located hospital occupational health unit can often help to facilitate access to appropriate immunization procedures and more general advice on work-related health problems.

\section{The individual 'sick doctor'}

When fellow medical colleagues are affected by health problems, they should be well placed to have access to the best possible investigation and treatment, but this ideal is not always realized. Particularly when illness affects the personality or behaviour of the individual there is often reluctance to seek professional advice and offers of assistance from concerned colleagues often go unheeded. It is when such problems, whether caused by alcohol, psychiatric or organic illness, encroach upon the quality and safety of patient care that ethical concerns can arise about the right action to take. Although all hospital doctors work within a contractual relationship with the Health Authority, their hierarchical relationships with one another are less well defined. For junior hospital staff there is general acceptance of a 'line management' structure, at least in professional terms, to the consultant in administrative charge of the department. Within this framework, deviations from normal health which encroach on work capacity would normally be detected and dealt with. Where illness affects the work capacity of a consultant colleague, who has more professional independence, there is greater scope for significant health problems to go unattended. Informal mechanisms for dealing with such problems include a direct approach appealing to the 'sick doctor' to seek help, or an indirect approach through anonymous reporting to the National Counselling and Welfare Service for Sick Doctors. More formal action can be taken by involving the 'Three Wise Men' system within the hospital or in extreme cases by involving the Health Committee of the General Medical Council. 
These cumbersome arrangements have arisen as a result of loose reporting mechanisms within the management structures, linked with a sense of professional etiquette which cautions against implied criticism of colleagues. Recent changes in the consultant contract, which define more clearly the working relationships with general management, are likely to bring abnormal behaviour or altered performance at work under closer scrutiny, with opportunities for earlier consideration of associated health-related issues. The consultant occupational physician in the NHS is accustomed to dealing with the interactions between health and work in every group of staff and is well placed to extend this role to medical staff themselves. The surgeon with multiple sclerosis, the cytologist with impaired vision, the physician with manic depression, are all examples which the NHS occupational physician encounters and every effort is made to plan suitable rehabilitation within a framework which ensures acceptable levels of care to patients. With increasing frequency, personal concerns about HIV infection are considered on a highly confidential basis following appropriate ethical guidelines.

\section{The doctor as a manager}

For those doctors who have an executive role in the organization of their department, the use of the $\mathrm{OH}$ service as an information and advisory resource in relation to health and safety at work may be of considerable assistance for fulfilment of duties falling within the spectrum of risk management. The COSHH regulations ${ }^{7}$ require health authorities to consider the work processes using chemical and microbiological substances which can be harmful to health. An assessment is required for each process, taking into account the known toxicology of the hazardous material. For some materials, arrangements for environmental monitoring will be necessary, involving the measurement of airborne contaminants by an occupational hygienist. In a smaller proportion, it will be necessary to undertake health surveillance of employees, and this may involve a physical examination and $\mathrm{a}$ biological assessment of exposure. $\mathrm{OH}$ services in the NHS have a major role to play in these $\stackrel{\varrho}{c}$ developments by advising what action to take, but it is the manager who will have the responsibility to ensure that the legal requirements are fulfilled.

\section{Careers in occupational medicine within the NHS}

Although occupational medicine is currently the smallest specialty in the NHS, its claim to be the most rapidly expanding (from one consultant post in 1981 to 50 in 1991) has been of interest to junior $\vec{\omega}$ doctors considering their choice of career. The $\stackrel{S}{\circ}$ Faculty of Occupational Medicine's Specialty $\bar{C}$ Advisers in NHS regions report a steady stream of 3 . enquiries from young medical graduates at an early $\infty$ stage of their careers. Before considering this $\infty$ possibility a broad general professional training of $\mathrm{N}$ 3 years (such as exists in general medicine or 8 general practice) is desirable prior to entering $\omega$ Higher Specialist Training.

Considerable scope exists for training within the NHS and particularly in departments where services are also provided to a range of other industries. An establishment of 26 NHS senior registrar posts has been agreed recently with the Departmenf of Health's Joint Planning Advisory Committe (JPAC) and this will enhance training prospect further. A move to occupational medicine, how ever, is one which should be considered with particular care for it may not be suited to those who thrive on the high drama of the operating theatre or the intensive care unit. The specialty combines the strategic approach of preventing ill health in the working population with the maintenance of clinical skills. For those capable of working well within a multidisciplinary team, there are opportunities for a stimulating career.

\section{Acknowledgements}

Thanks to Dr David Watt and Professor R.I. McCallum for helpful comments and Mrs Sheila Marshall for preparing the manuscript.

\section{References}

1. Ministry of Health and Scottish Home and Health Department, Central and Scottish Health Service Councils. The Care of the Health of Hospital Staff. Report of the Joint Committee. HMSO, London, 1968.

2. Healey, B. Occupational Health Services in the NHS. Occup Health 1982, 34: 474-476.

3. International Labour Organisation Conference, Recommendation 112. ILO, Geneva, 1959.

4. Successful Health and Safety Management. Health and Safety Executive. HMSO, London, 1991.

5. Waclawski, E.R., McAlpine, L.G. \& Thomson, N.C.A Occupational asthma in nurses caused by chlorhexidine and alcohol aerosols. Br Med J 1989, 298: 929-930.

6. First Aid at Work. Health and Safety (First Aid) Regulations 1981 and Guidance. Approved code of practice 1990. HMSO, London, 1990.

7. Control of Substances Hazardous to Health Regulations and Approved Code of Practice. Health and Safety Commission. HMSO, London, 1988.

8. Harrington, J.M., Philip, R. \& Seaton, A. Undergraduate occupational health teaching in British medical schools. $J R$ Coll Physic Lond 1989, 23: 24-26. 